\title{
O Aglomerado Urbano de Jundiaí (SP) e os desafios para a mobilidade metropolitana paulista
}

\author{
The Jundiaí Urban Agglomeration and challenges \\ to São Paulo's metropolitan mobility
}

Adriana Fornari Del Monte Fanelli Wilson Ribeiro dos Santos Junior

\section{Resumo}

Este artigo enfoca a inserção do Aglomerado Urbano de Jundiaí (AUJ) no ambiente metropolitano paulista, objetivando fornecer elementos para a compreensão da mobilidade intrametropolitana já que essa "aglomeração urbana instersticial" (Emplasa, 2011) se localiza entre as Regiões Metropolitanas de São Paulo e Campinas com as quais mantém fortes conexões. Pretende ampliar o conhecimento dessa organização regional recém criada, utilizando dados demográficos e indicadores socioeconômicos. Analisa a mobilidade como um fator estrutural da forma urbana do AUJ a partir das relações de interdependência das cidades que o compõem, do estudo dos vetores de expansão intrametropolitana do AUJ, da dispersão urbana ao longo das rodovias e da ampliação da segregação socioespacial que acompanha a redistribuição da população no contexto regional.

Palavras-chave: aglomerado urbano de Jundiaí; redes de cidades; segregação socioespacial; mobilidade urbana; estudos da metrópole.

\begin{abstract}
This paper focuses on the inclusion of the Jundiai Urban Agglomeration (JUA) in the São Paulo metropolitan environment aiming to provide elements for the understanding of intrametropolitan mobility, as this "interstitial urban agglomeration" (Emplasa, 2011) is located between the metropolitan areas of São Paulo and Campinas, with which it has strong connections. The paper intends to expand the knowledge about this newly created regional organization, using demographic data and socioeconomic indicators. It analyzes mobility as a structural factor of the urban form of the JUA based on the interdependence relations of its component cities, on the study of the vectors of the intrametropolitan expansion of the JUA, on the urban sprawl along the highways and on the expansion of the socio-spatial segregation th at a ccom pani es the re di stributi on of the population in the regional context.
\end{abstract}

Keywords: urban agglomeration of Jundiaí; networks of cities; socio-spatial segregation; urban mobility; metropolis studies. 


\section{Introdução: as tendências atuais dos processos recentes de metropolização no Brasil}

Este artigo procura analisar o papel do Aglomerado Urbano de Jundiaí na mobilidade metropolitana paulista nos dias atuais, a partir da análise da evolução dos processos de metropolização brasileira contemporânea, seguindo alguns pesquisadores como Ascher, Queiroga, Sassen e Moura.

Até 1950, a rede urbana brasileira era fragmentada, esparsa, desarticulada e centralizada nas grandes cidades, principalmente no caso da Macrometrópole Paulista, ou seja, era formada por cidades com um único centro (Ascher, 2001), onde se agrupavam atividades que necessitavam de maior acessibilidade, caracterizando um espaço geográfico adensado e multifuncional.

Além dos equipamentos do poder, da religião e do comércio, instalaram-se todos os tipos de atividades e de serviços que deveriam dispor do melhor acesso possível e da frequência máxima. Com isso, foram atraídas novas infraestruturas de transporte realimentando 0 adensamento e a centralização. (Ascher, 2001, p. 63)

Essas grandes cidades nucleavam o sistema de hierarquia urbana, concentrando a oferta de serviços na escala regional e/ou estadual.

Nos anos de 1960, a partir de uma ação do Estado, foram implantadas infraestruturas urbanas que impulsionaram a expansão do capital industrial e da indústria de base, e aos poucos
[...] a cidade absorveu concepções taylorianas e fordianas, e o recorte das atividades urbanas em funções elementares: procurou-se otimizar de maneira separada a produção industrial, as finanças, 0 comércio, a moradia e o lazer. A centralidade única foi detonada em razão do zoneamento e da centralidade múltipla: business district industrial, zonas industriais, centros comerciais, zonas de moradias, etc. (Ascher, 2001, p. 63)

No final dos anos 1960 e década de 1970, a expansão da economia brasileira e o avanço da industrialização para o interior do Estado, favoreceram o surgimento e desenvolvimento de aglomerações urbanas, consequentemente expandindo a rede urbana nesse processo de interiorização, que se deu, num primeiro momento, de forma linear, acompanhando os eixos de grande circulação, como no caso deste objeto de estudo, as Rodovias Anhanguera e Bandeirantes. Essa desconcentração industrial tomou força principalmente na década de 1980 quando inicialmente atingiu um raio de cerca de $150 \mathrm{~km}$ da capital, englobando Campinas, Jundiaí, Sorocaba, Baixada Santista e Vale do Paraíba (Queiroga, 2007, p. 43).

Induzidas por uma dinâmica econômica de acumulação de capital e pelas inovações tecnológicas, as transformações físicas, funcionais e espaciais nessas aglomerações urbanas promoveram a fragmentação e dispersão das manchas urbanas por um vasto território, reestruturando-o.

Paralelamente passa a ocorrer um aumento do setor de prestação de serviços para essas empresas, e esse ramo tem um importante papel no desenvolvimento econômico, 
requerendo a localização estratégica no território, de preferência nas proximidades das grandes cidades. As indústrias, aliadas aos setores de serviços, ${ }^{1}$ desencadeiam a dispersão urbana no território (Sassen, 1998).

Surgem também os condomínios residenciais fechados ao longo das rodovias, demandando ao Estado a implantação de outras infraestruturas, especialmente voltadas para a mobilidade regional para suportar esse crescimento fragmentado.

Atualmente a metropolização contemporânea vêm-se manifestando na forma de arranjos urbano-regionais ${ }^{2}$ (Moura et al., 2012), atingindo uma escala mais ampla, dinâmica e complexa, conectando o urbano e o regional, o local, o regional, e o nacional e o global.

No início do século XXI, os aglomerados urbanos tiveram sua importância amplificada na evolução dos fluxos de comunicação das cidades e atualmente são essenciais no sistema metropolitano, calcado nos avanços tecnológi$\cos$, de informação e de telecomunicações da última década, transpondo as fronteiras entre as regiões metropolitanas.

Nesse contexto, o Aglomerado Urbano de Jundiaí que, até o final dos anos de 1980, tinha um caráter industrial, agora apresenta a predominância do setor de serviços e comércio (ver Tabela 5) e, mais especificamente nos últimos anos, o setor de logística, pertencente à área de serviços, tem crescido bastante, aproveitando-se da posição geográfica, proporcionando a melhor acessibilidade às metrópoles de São Paulo e Campinas e ao Aglomerado Urbano de Sorocaba.

\section{Aglomerado Urbano de Jundiaí (AUJ)}

0 AUJ é a mais recente unidade regional do estado de São Paulo, constituída pelos municípios de Cabreúva, Campo Limpo Paulista, Itupeva, Jarinu, Jundiaí, Louveira e Várzea Paulista. 0 Projeto de Lei Complementar (PLC) 13/2011, que criou o AUJ, foi sancionado pelo governador do estado de São Paulo, após aprovação pela Assembleia Legislativa, em 24 de agosto de 2011. Integra a Macrometrópole Paulista (Emplasa, 2012), cidade-região formada por 153 municípios que rodeiam a cidade de São Paulo, num raio de aproximadamente 200 quilômetros e conta com $72 \%$ dos habitantes do Estado, 95\% desses vivendo nas áreas urbanas, com $80 \%$ do PIB estadual e aproximadamente $27 \%$ do PIB brasileiro (IBGE, 2010). As constantes transformações nesse território macrometropolitano, promovidas pela densidade das relações físico-territoriais e dos meios técnico-informacionais, produzem impactos na estrutura socioeconômica, nas relações de classe, na estratificação de renda, na organização do trabalho, no mercado imobiliário, na produção social, no consumo e nas atividades de serviços da região.

A dinâmica da Macrometrópole Paulista produz espaços de concentração e dispersão urbana. Os fluxos intrametropolitanos de mobilidade associados a aspectos sociais, econômicos, produtivos e tecnológicos intensificam o espaIhamento dos espaços fragmentados e segregados no território. Nesse contexto, ganha especial relevo o papel estruturador das conexões 
rodoviárias existentes para a análise do crescimento urbano do Aglomerado Urbano de Jundiaí, especialmente das rodovias Anhanguera e Bandeirantes (eixo São Paulo-Campinas).

A grande concentração de pessoas e atividades ao longo desses eixos rodoviários levou ao crescimento da mancha urbana para além das fronteiras administrativas das cidades, tornando-se engrenagens de uma rede de expansão, produção e integração de novos espaços urbanos, demarcados pela segregação e exclusão social.

Com o desenvolvimento do sistema de transportes, com a substituição das linhas férreas pelas novas rodovias, e com a disseminação do uso do automóvel, a concentração da população nas áreas centrais das cidades diminuiu, expandindo-se para as periferias.
Os movimentos simultâneos e aparentemente contraditórios de dispersão e concentração geraram uma dinâmica mobilidade intraurbana e intrametropolitana em escala regional, acompanhada, via de regra, pela implantação de infraestruturas rodoviaristas como as novas autoestradas, anéis viários urbanos que, além de introduzirem transformações visuais urbanísticas, atraíram a localização de novos espaços comerciais e empresariais.

A Macrometrópole Paulista apresenta-se como um território denso, mas descontínuo, de áreas urbanizadas, e articulado, de forma heterogênea, pela intensificação do fluxo de pessoas, mercadorias e informações, formando muitas vezes espaços fragmentados e policêntricos (Ascher, 2001), de acordo com os atrativos de determinada região. Ao mesmo tempo

Figura 1 - Macrometrópole Paulista

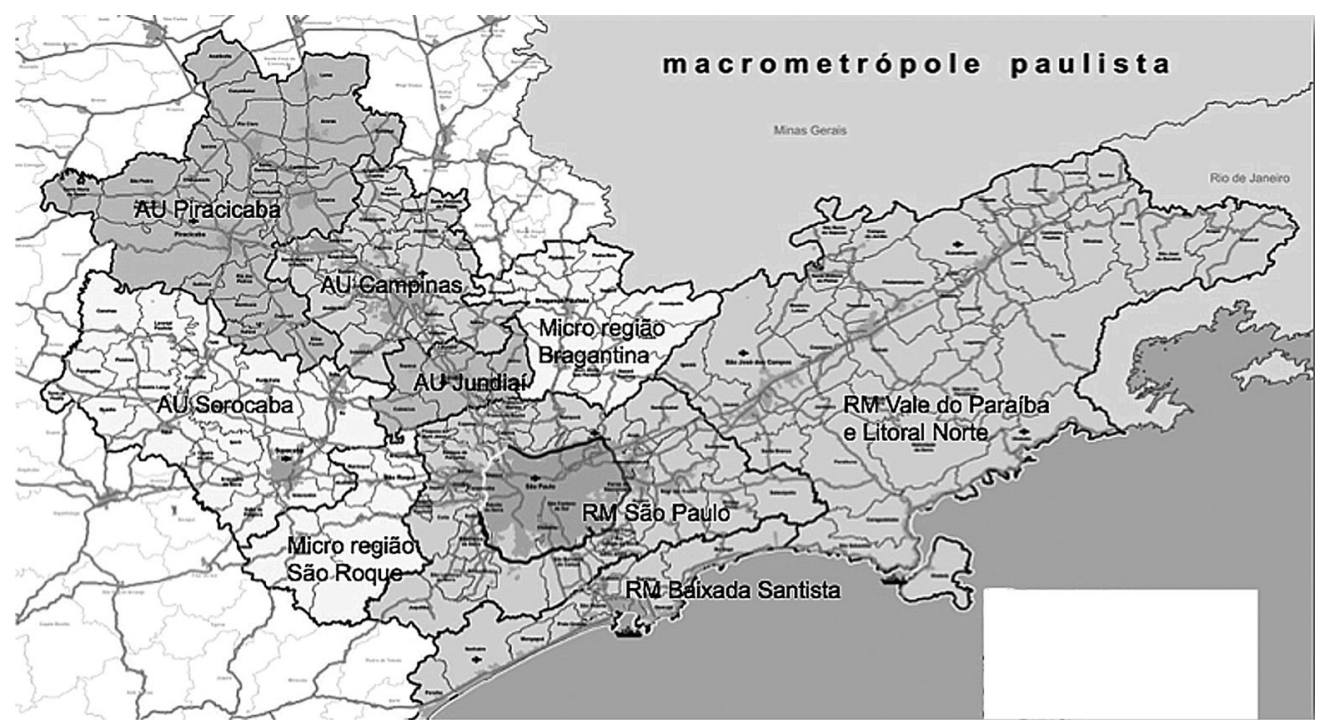

Fonte: Emplasa (2012). Disponível em: http://www.emplasa.sp.gov.br/emplasa/ 
Figura 2 - Aglomerado Urbano de Jundiaí: divisão municipal
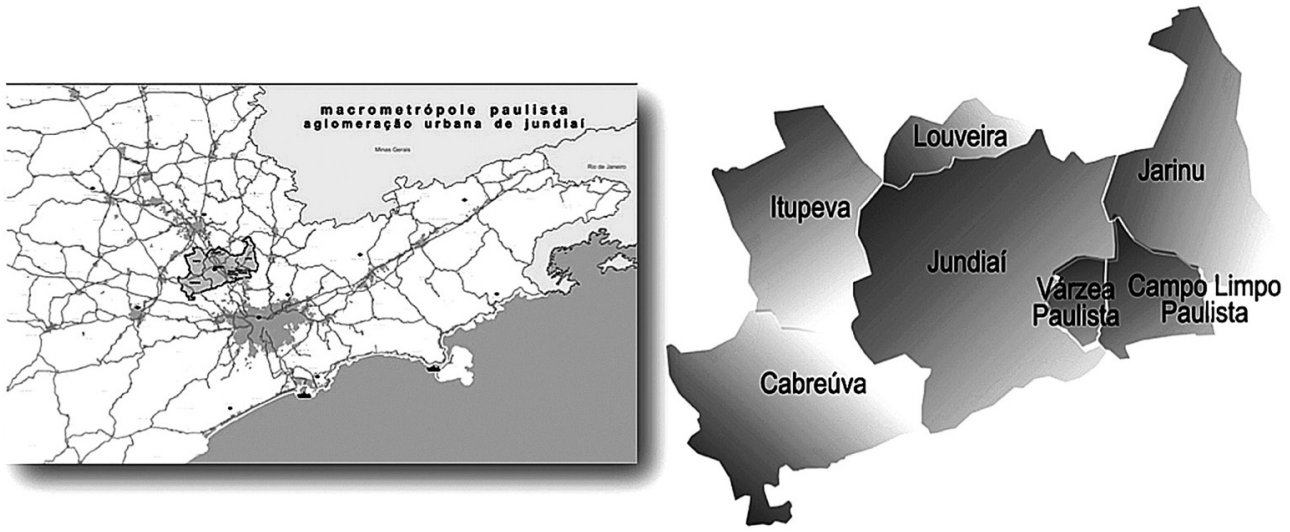

Fonte: Emplasa (2012). Disponível em: http://www.emplasa.sp.gov.br/emplasa/

atua como um espaço contínuo que se expressa através do aumento do crescimento da conurbação de cidades ou da perda dos limites claros entre elas. Muitas vezes, a conurbação além de física é também funcional, numa relação estreita de interdependência entre cidades, coesionando um sistema de redes interurbanas.

[...] técnica, ciência e informação se apresentam de forma variável no meio, constituindo regiões mais ou menos concentradas, construindo redes globais de informações econômico-territoriais, com diferentes graus de acessibilidade. Cada vez mais, informação é poder. Nas regiões mais densas deste meio há condições para a constituição de novos processos de urbanização, dada a base técnica e informacional que permite novos arranjos produtivos e distributivos. (Queiroga e Benfatti, 2007, p. 42)

A partir das características das cidades do AUJ, é possível verificar o tipo e o grau de interdependência entre elas, compreendendo os possíveis vetores de crescimento da região, e consequentemente, os processos de segregação socioespacial dentro deles.

\section{Estruturação dos territórios metropolitanos contemporâneos}

0 AUJ localiza-se num corredor de infraestrutura urbana, no cruzamento de duas das mais importantes rodovias do estado de São Paulo, a Anhanguera e a Bandeirantes, que permitem um fácil acesso aos dois principais aeroportos do Estado, o de Cumbica, em GuaruIhos, e o de Viracopos, em Campinas, com as rodovias D. Gabriel Bueno Couto, que conecta o AUJ ao Aglomerado Urbano de Sorocaba (AUS), e João Cereser, que conecta a Microrregião Bragantina.

As possibilidades de acesso ao transporte aéreo de carga e a presença das rodovias 
Figura 3 - Distrito Industrial e condomínios ao longo da Rodovia D. Gabriel Paulino Bueno Couto

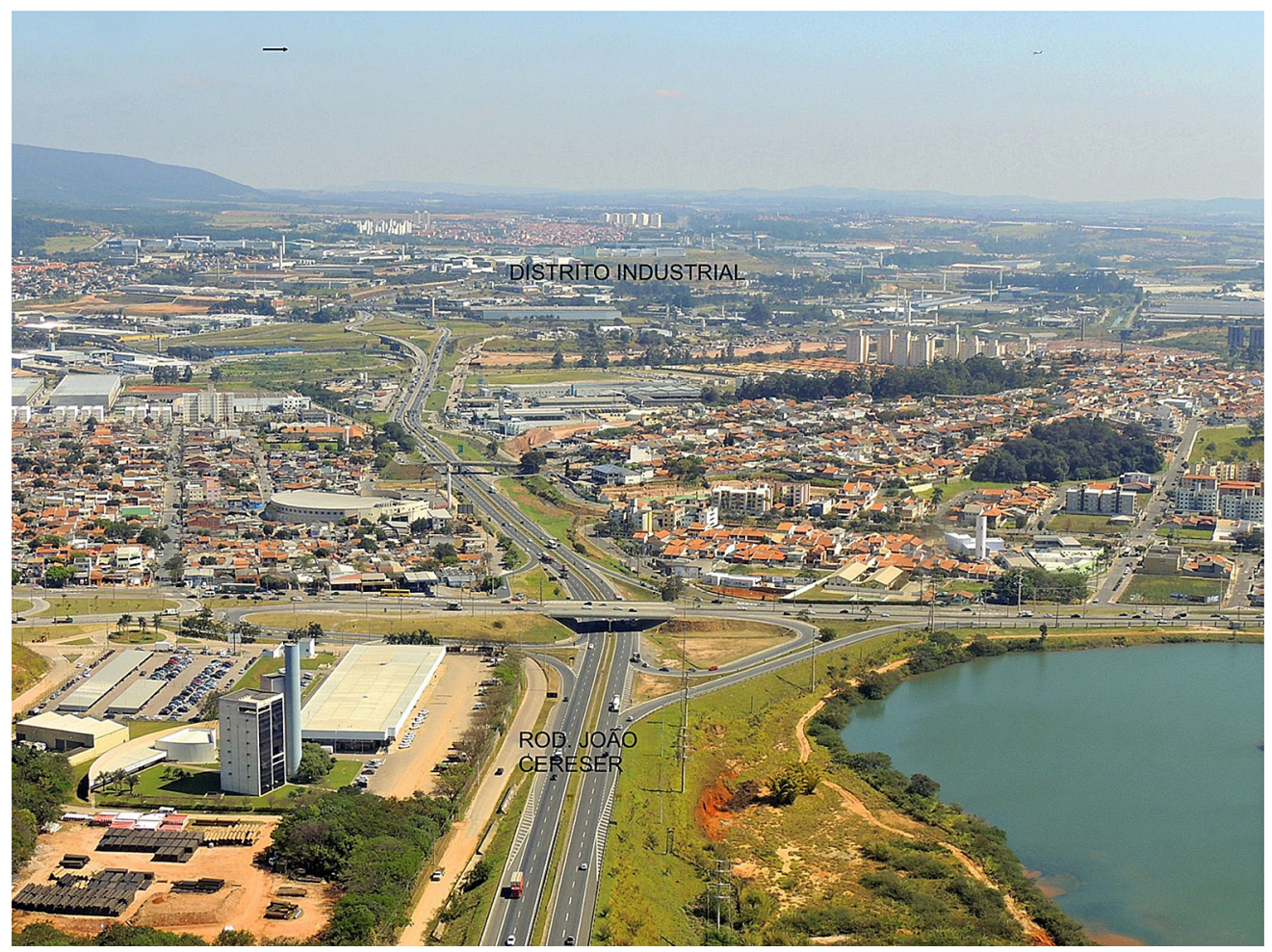

Fonte: Foto aérea executada por Adriana Del Monte, em 28/8/2013.

continuam atraindo diversas indústrias multinacionais e também setores de logísticas ao AUJ, ampliando a internacionalização da região. Esses novos empreendimentos, instalando-se simultaneamente na região, buscam maior acessibilidade às regiões metropolitanas e ao mesmo tempo induzem ao aumento de veículos nas rodovias, causando novos congestionamentos onde não eram frequentes.

0 AUJ possui um parque industrial com mais de quinhentas empresas, entre elas estão gigantes como Renault/Nissan, Frigor Hans, Parmalat, Coca-Cola, Ambev Sifco, Mahle, Siemens, Foxconn, Itautec, Rexam, Akzo Nobel, Fidelity Information Services. As atividades dessas empresas multinacionais, no entanto, vêm sendo implantadas, diferentemente do que ocorria anteriormente, em cidades menores da rede regional de cidades, ampliando o fluxo migratório e imigratório para a região macrometropolitana. 
Já é fato razoavelmente conhecido que a Região Metropolitana de São Paulo não é mais um grande polo de absorção de migrantes internos e externos, papel que desempenhou durante a maior parte do século XX. Na primeira década do $X X I$ houve um expressivo saldo negativo entre os que entraram e os que saíram. Chegaram 100 mil pessoas e partiram 800 mil somente para 0 interior do estado. 0 que não é tão conhecido é o novo perfil migratório que esses números, de certa forma, escondem. 0 fluxo já não se explica pela dinâmica da indústria e do emprego formal que antes atraía novos moradores. A grande novidade é o fenômeno da reversibilidade - ou seja, as permanências tendem a encurtar-se e o movimento se caracteriza por idas e vindas, além dos retornos definitivos. (Ferrarri, 2011, p. 84)

0 crescimento dessas indústrias é cada vez mais sensível à disponibilidade da informação, do processamento de telecomunicações, bem como da proximidade de transporte aéreo para facilitar o ponto a ponto de contatos entre muitos locais dispersos, aumentando assim a capacidade de integração dessas empresas às diferentes redes (Sassen, 2008) da economia mundial.

O AUJ integra Jundiaí, Cabreúva, Campo Limpo Paulista, Itupeva, Jarinu, Louveira e Várzea Paulista numa rede de cidades situadas ao longo de rodovias, ou eixos de infraestruturas de circulação e que se articulam num intricado sistema funcional de relações na escala regional, buscando aproveitar vantagens logísticas e consequentemente econômicas, ampliando a presença do AUJ na Macrometrópole Paulista.

\section{A evolução da população e da mancha urbana no Aglomerado Urbano de Jundiaí}

A cidade de Jundiaí é o centro da aglomeração urbana que compreende Jundiaí, Cabreúva, Campo Limpo Paulista, Itupeva, Jarinu, Louveira e Várzea Paulista, com uma população de cerca de 700 mil habitantes, onde Jundiaí participava, em 2010, com 370.126 habitantes desse total (Seade, 2010).

Jundiaí concentra aproximadamente $53 \%$ de toda a população do aglomerado e situa-se num entroncamento rodo-ferroviário importante entre as Regiões Metropolitanas de Campinas e São Paulo e o Aglomerado Urbano de Sorocaba, ocupando uma posição privilegiada dentro da Macrometrópole Paulista.

A espacialização desse poderoso nó de fluxos viários, ferroviários e aeroviários, que estrutura o AUJ, tornou-se um fator especialmente importante de promoção da dispersão e fragmentação da urbanização metropolitana, pelo fácil acesso dos novos núcleos urbanos a rodovias e ferrovias, pela proximidade aos aeroportos internacionais, pelo fortalecimento da infraestrutura e comunicação, além do aumento do desenvolvimento econômico no conjunto da região com o espalhamento de centros logísticos de distribuição de grandes redes varejistas e instalação de novas unidades produtivas.

Através da imagem aérea (Figura 5), verifica-se o alargamento e a expansão da 
Figura 4 - Rodovia D. Gabriel Paulino Bueno Couto

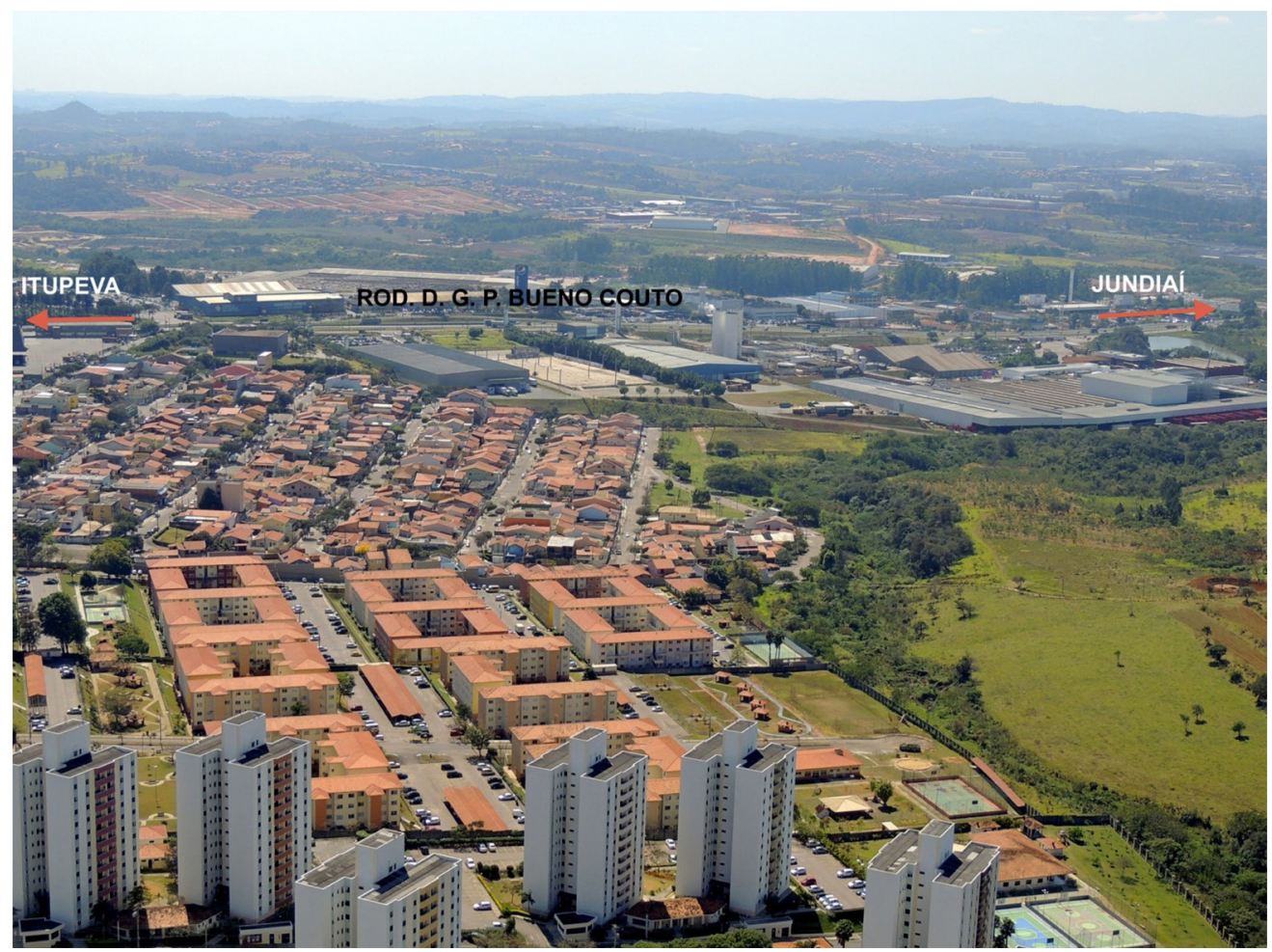

Fonte: Foto aérea realizada por Adriana Del Monte, em 28/8/2013.

mancha urbana em direção ao entroncamento rodoviário das rodovias Bandeirantes, Anhanguera e Gabriel Paulino Bueno Couto (SP 300), além de uma certa dispersão urbana, principalmente na direção de Louveira e na direção de Itupeva e Cabreúva.

Algumas cidades do aglomerado apresentam alta densidade populacional como é o caso das três cidades atualmente conurbadas: Campo Limpo Paulista, Várzea Paulista (ambas com $100 \%$ de área urbanizada) e Jundiaí (com $95 \%$ de área urbanizada).
0 processo de conurbação pode ser observado entre os municípios de Jundiaí, Várzea Paulista e Campo Limpo Paulista que têm, nos últimos anos, apresentado um processo acelerado de urbanização (ver Tabela 1), polarizado por Jundiaí.

Entre os vários fatores que explicam essas conurbações, destacam-se os de natureza territorial tais como a área disponível para urbanização, ou mesmo, o tamanho do território da cidade, como no caso de Várzea Paulista que, pela ocupação adensada de todo o território 
Tabela 1 - Grau de urbanização (\%)

\begin{tabular}{c|c|c}
\hline Localidade & $\mathbf{2 0 0 0}$ & $\mathbf{2 0 1 0}$ \\
\hline Cabreúva & 77,83 & 84,75 \\
Campo Limpo Paulista & 97,7 & 100,00 \\
Itupeva & 73,6 & 86,84 \\
Jarinu & 64,45 & 77,28 \\
Jundiaí & 92,83 & 95,7 \\
Louveira & 91,57 & 96,15 \\
Várzea Paulista & 100,00 & 100,00 \\
\hline
\end{tabular}

Fonte: Seade (2010). Disponível em: www.seade.gov.br

urbanizável disponível, expandiu a mancha urbana em direção a Jundiaí, com a qual mantém uma interdependência muito grande.

Em Jundiaí, a partir de 1998, o decreto estadual 43.284 instituiu uma zona de conser- vação hídrica composta pelas bacias dos rios Capivari e Jundiaí-Mirim, propiciando uma baixa densidade territorial nessas áreas. Em 2004, a lei complementar 417 delimitou uma área de preservação ambiental na Serra do Japy (zona de conservação da vida silvestre), impedindo qualquer novo tipo de ocupação ou transformação do território. Somente o território de gestão da Serra do Japy corresponde a um terço do território jundiaiense (Figura 6). A exclusão dessas áreas para ocupação urbana resultou na ocupação quase total do restante do território e produziu, em Jundiaí, um índice de 95\% de área urbanizada que se expandiu além das fronteiras do município, conurbando-se com Várzea Paulista e Campo Limpo Paulista.

Campo Limpo Paulista conta com um setor industrial desenvolvido, apresenta alta densidade populacional e uma forte dependência do setor de serviços e de comércio de Jundiaí, fatores que contribuíram para o processo de conurbação, conforme registrado na Figura 7. 
Figura 5 - Zonas de conservação e preservação ambiental

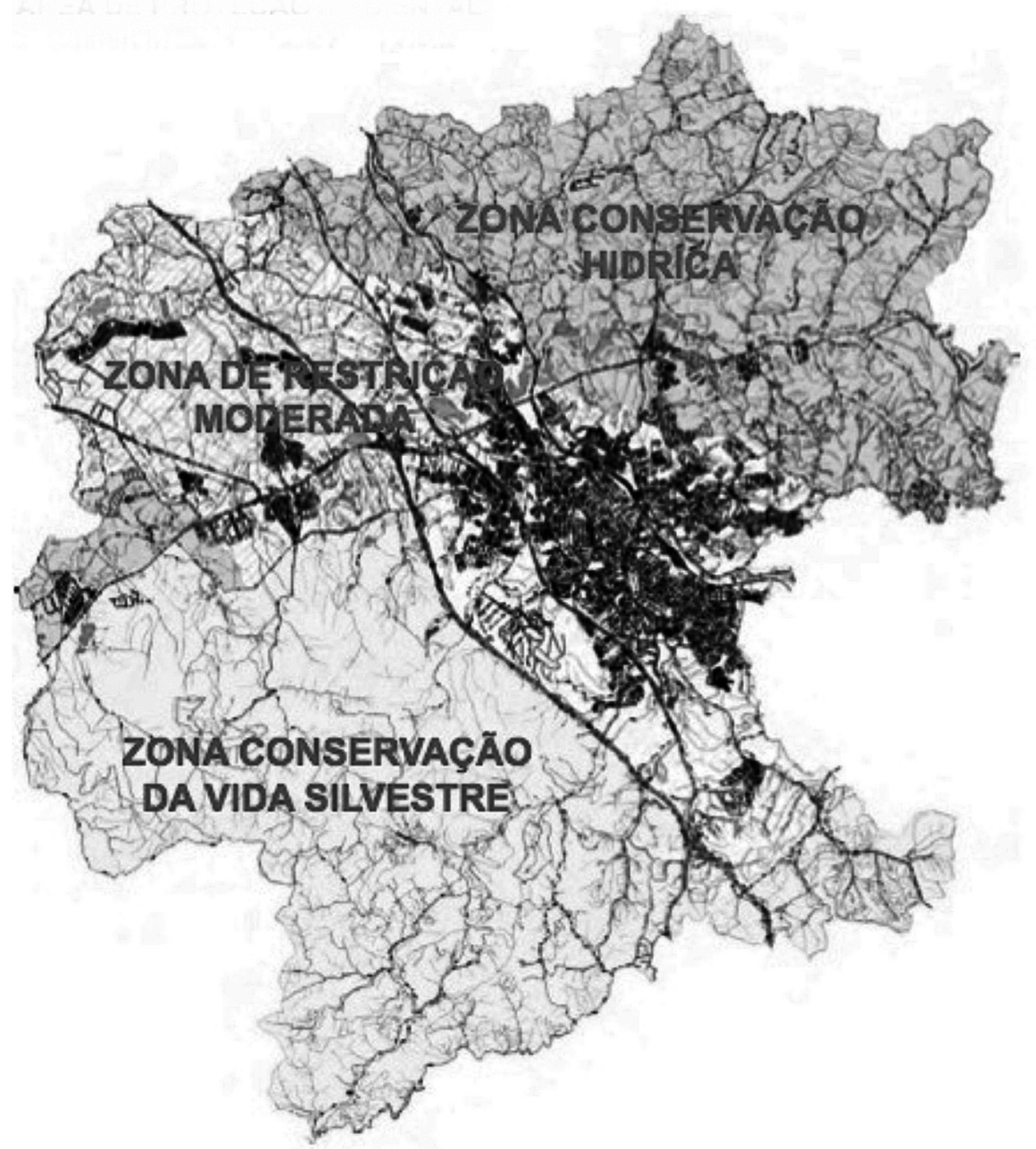

Fonte: Prefeitura Municipal de Jundiaí (2012). Disponível em: http://cidade.jundiai.sp.gov.br/PMJSITE/portal.nsf/V03.02/smpm_mapas?OpenDocument 


\section{Figura 6 - Mancha urbana 2013}

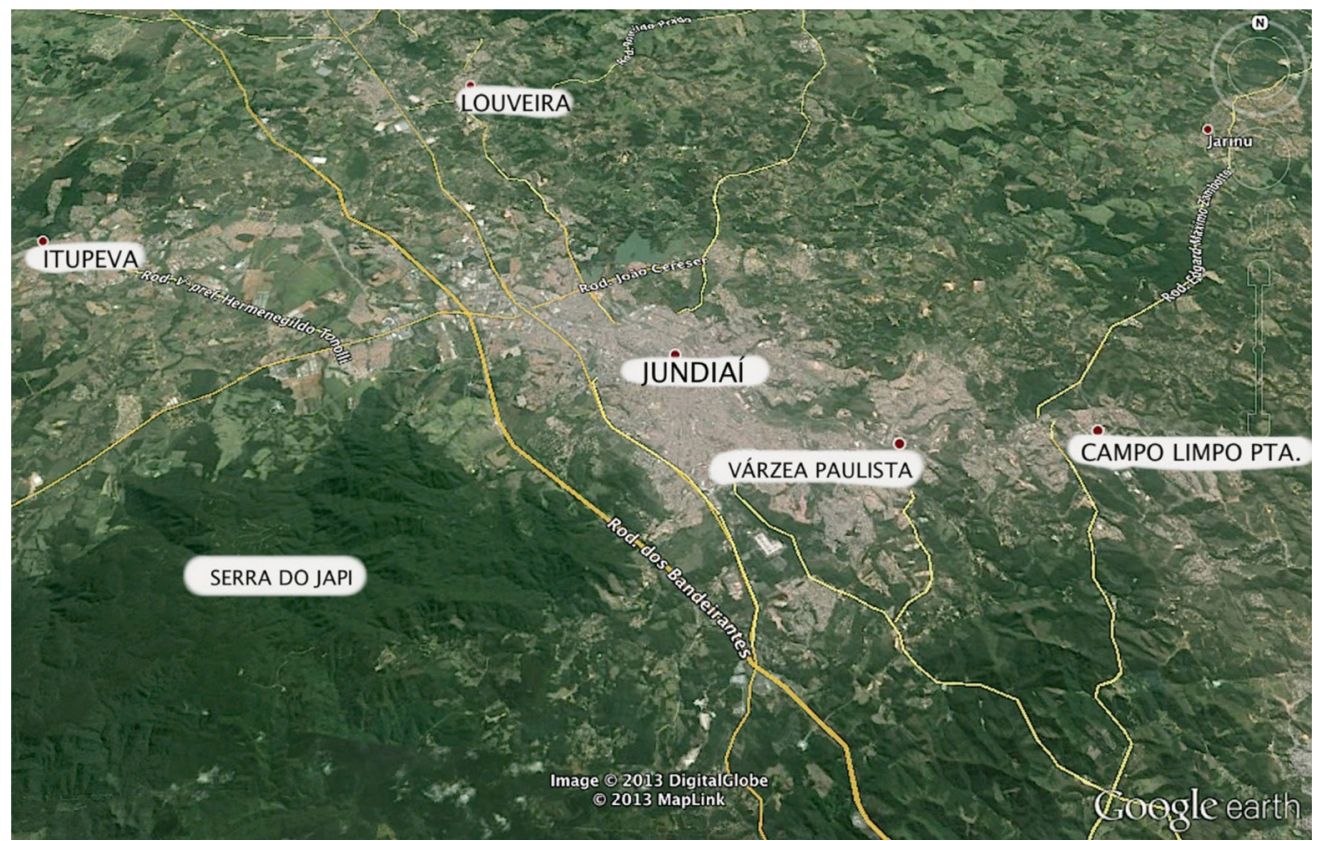

Fonte: Imagem do Google Earth. Acesso em 10/6/2013.

Considerando que Itupeva ampliou sua participação no contingente populacional do AUJ de $4,51 \%$, em 2000 , para $6,42 \%$, em 2010 , e apresenta o maior índice de crescimento geométrico da região, da ordem de $5,53 \%$ ao ano (Seade, 2010), evidencia-se o surgimento de um vetor intrametropolitano de crescimento nessa direção. A alta taxa geométrica de crescimento apresentada por Itupeva pode ser justificada pela implementação do Distrito Industrial, facilitado pela extensão do gasoduto Brasil-Bolívia, pela instalação de shoppings conectados à rodovia, pelo turismo ecológico e rural, além dos grandes parques temáticos. Com 0 desenvolvimento econômico de Itupeva, a forma urbana da região alterou-se com a implantação de um grande número de condomínios residenciais horizontais fechados, confirmando um vetor de dispersão urbana e de crescimento populacional no sentido de Jundiaí a Itupeva. 
Tabela 2 - Taxa de crescimento geométrico anual (2000/2010)

\begin{tabular}{l|c|c}
\hline \multicolumn{1}{c|}{ Unidade territorial } & Número de municípios & TGCA (\% 2000/2010) \\
RM de São Paulo & 39 & 0,99 \\
RM Baixada Santista & 9 & 1,22 \\
RM Campinas & 19 & 1,83 \\
RMVPLN & 39 & 1,31 \\
AU Jundiaí & 7 & 1,88 \\
AU Piracicaba & 22 & 1,23 \\
AU Sorocaba & 22 & 1,71 \\
MR São Roque & 5 & 1,25 \\
MR Bragantina & 11 & 1,56 \\
Macrometrópole & 173 & 1,17 \\
Estado de São Paulo & 645 & 1,10 \\
Brasil & 5.565 & 1,17 \\
\hline
\end{tabular}

Fonte: Seade (2012). Disponível em: http://www.seade.gov.br

Tabela 3 - Evolução da população no AUJ

\begin{tabular}{|c|c|c|c|c|c|}
\hline \multirow{2}{*}{ Municípios } & \multicolumn{2}{|c|}{ Área $\left(\mathrm{km}^{2}\right)$} & \multirow{2}{*}{$\begin{array}{c}\text { Densidade } \\
\text { demográfica } \\
\left(\mathrm{hab} / \mathrm{km}^{2}\right)\end{array}$} & \multirow{2}{*}{$\begin{array}{l}\text { População } \\
2000\end{array}$} & \multirow{2}{*}{$\begin{array}{c}\text { População } \\
2010\end{array}$} \\
\hline & Abs. & $\%$ & & & \\
\hline Cabreúva & 259,81 & 20,46 & 160,13 & 33.100 & 41.604 \\
\hline Campo Limpo Paulista & 80,05 & 6,30 & 925,37 & 63.724 & 74.074 \\
\hline Itupeva & 200,52 & 15,79 & 223,72 & 26.166 & 44.859 \\
\hline Jarinu & 207,67 & 16,35 & 114,83 & 17.041 & 23.847 \\
\hline Jundiaí & 431,97 & 34,01 & 856,83 & 323.397 & 370.126 \\
\hline Louveira & 55,35 & 4,36 & 670,74 & 23.903 & 37.125 \\
\hline Várzea Paulista & 34,63 & 2,73 & $3.092,64$ & 92.800 & 107.089 \\
\hline AU Jundiaí & $1.269,99$ & 100,00 & 550,18 & 580.131 & 698.724 \\
\hline Estado de São Paulo & $248.197,00$ & - & 166,25 & 36.969 .476 & 41.262 .199 \\
\hline
\end{tabular}

Fonte: Seade (2012). Disponível em: http://www.seade.gov.br 
Tabela 4 - Taxa de crescimento anual por cidade no AUJ (TGCA)

\begin{tabular}{c|c|c}
\hline \multirow{2}{*}{ Localidade } & $\begin{array}{c}\text { Taxa Geométrrica de Crescimento Anual } \\
\text { (em \% a.a.) }\end{array}$ & 2010 \\
\hline Cabreúva & População total & 2,35 \\
& População urbana & 3,22 \\
& População rural & $-1,42$ \\
\hline Campo Limpo Paulista & População total & 1,54 \\
& População urbana & 1,77 \\
\hline Itupeva & População rural & -100 \\
\hline & População total & 5,53 \\
& População urbana & 7,29 \\
\hline Jarinu & População rural & $-1,57$ \\
\hline Jundiaí & População total & 3,43 \\
& População urbana & 5,33 \\
& População rural & $-1,1$ \\
\hline Louveira & População total & 1,36 \\
& População urbana & 1,67 \\
& População rural & $-3,69$ \\
\hline
\end{tabular}

Fonte: Seade (2012). Disponível em: http://www.seade.gov.br/produtos/imp/index.php?page=tabela

Hoje, o AUJ detém a maior taxa de crescimento geométrico (TGCA) da Macrometrópole Paulista - 1,88\% de 2000 a 2010 -, enquanto a Região Metropolitana de São Paulo apresentou 0,99\% no mesmo período.

Porém, Jundiaí, acompanhando os indicadores das cidades-polo das demais regiões metropolitanas brasileiras, apresenta a menor taxa de crescimento anual (1,36\%) da população do aglomerado. Apesar disso, a população de Jundiaí corresponde ainda a 53\% do total do aglomerado urbano, um dos fatores que a reitera como polo centralizador da região.
A densidade demográfica de Várzea Paulista, de 3.092,64 hab/km², contrasta com as demais cidades. Campo Limpo Paulista, em segundo lugar, mesmo com muitas indústrias metalúrgicas, que ocupam extensas áreas territoriais, apresenta um adensamento populacional significativo, $925 \mathrm{hab} / \mathrm{km}^{2}$, bem distante de Várzea Paulista, uma cidade-dormitório, onde a maioria da população trabalha em Jundiaí ou em Campo Limpo Paulista.

Essa nova configuração urbana do AUJ promoveu o aumento dos deslocamentos populacionais, pendulares entre os municípios, 
confirmando o estreitamento das relações socioeconômicas.

A distinção entre o centro e periferia da maioria das cidades do AUJ deixou de existir com o surgimento de novas centralidades nas antigas periferias, impulsionadas por polos de serviço como supermercados, shoppings, parques, e pela criação de distritos industriais resultantes do espalhamento dos equipamentos produtivos por amplos territórios e que se interligam de forma autônoma com a Macrometrópole Paulista.

[...] esta urbanização que se estende para além das cidades em redes que penetram virtualmente todos os espaços regionais, integrando-os em malhas mundiais, representa, assim, a forma socioespacial dominante que marca a sociedade capitalista de Estado contemporânea em suas diversas manifestações, desde o centro dinâmico do sistema capitalista, até - e cada vez mais - as diversas periferias que se articulam dialeticamente em direção aos centros e sub-centros. (Monte-Mór, 1994, p. 171)

Esse novo ambiente de urbanização contemporânea confirma a importância dos sistemas de circulação e transporte e a falência das condições de acessibilidade e mobilidade, devido aos intensos fluxos de veículos que transformam rodovias de alta velocidade em avenidas metropolitanas de baixa velocidade.

\section{A rede de cidades no AUJ}

Apesar de Jundiaí, cidade-polo do aglomerado urbano, apresentar maior número de habitantes e maior área territorial, não se destaca em todos os setores produtivos como cidade principal. Na realidade, existem circuitos muitos específicos dos quais participam as cidades do aglomerado, remetendo, como aponta Sassen, à existência de diferentes circuitos articulando as redes de cidades.

A adoção da perspectiva de uma dessas cidades revela a diversidade e a especificidade de sua localização em alguns, ou em muitos, desses circuitos. Essas emergentes geografias intercidades começam a funcionar como infraestrutura para várias formas de globalização. A primeira etapa seria identificar os circuitos globais específicos dos quais uma cidade faz parte. Eles variam conforme a cidade, dependendo das características específicas de cada uma, da mesma maneira que, em cada circuito, os grupos de cidades são diferentes. Isto mostra que as diferenças e características especiais das cidades são importantes, e que a concorrência entre as cidades é menor do que parece, ou seja, certa divisão global, ou regional, de funções, estaria desempenhando um papel mais importante do que parece. (Sassen, 2008)

No caso do AUJ, isso é visível quando verificamos o número de estabelecimentos por setor produtivo em cada cidade, ou seja, apesar de serem cidades independentes, são cidades complementares funcionalmente e estabelecem entre si uma relação de cooperação e interdependência.

Para essa análise, é importante relacionar não só o número de estabelecimentos entre as cidades do aglomerado, mas também entre os próprios estabelecimentos da cidade para que se verifique a especificidade de cada uma delas. 
Tabela 5 - Estabelecimentos por setores

\begin{tabular}{l|r|r|r|r|r|r|r}
\hline Estabelecimentos & Jundiaí & $\begin{array}{c}\text { Várzea } \\
\text { Paulista }\end{array}$ & Cabreúva & $\begin{array}{c}\text { Campo Limpo } \\
\text { Paulista }\end{array}$ & Louveira & Itupeva & Jarinu \\
\hline Agropecuários & 175 & 4 & 72 & 8 & 53 & 79 & 78 \\
Industriais & 1.286 & 378 & 178 & 141 & 156 & 257 & 85 \\
Comerciais & 3.797 & 454 & 245 & 325 & 297 & 400 & 153 \\
Serviços & 3.683 & 250 & 187 & 207 & 209 & 282 & 121 \\
Total & 8.941 & 1.086 & 712 & 681 & 715 & 1.018 & 437 \\
\% no AU & $65,79 \%$ & $7,99 \%$ & $5,24 \%$ & $5,01 \%$ & $5,26 \%$ & $7,49 \%$ & $3,22 \%$ \\
\hline
\end{tabular}

Fonte: IBGE (2010). Disponível em: http://cidades.ibge.gov.br/xtras/home.php

0 setor de serviços e comércios de Jundiaí é extremamente importante para toda a região, ocupando $83 \%$ de seus estabelecimentos. Esse setor sustenta boa parte das necessidades do aglomerado urbano, proporcionando um fluxo constante e pendular entre as cidades.

Em Campo Limpo Paulista, 68\% dos estabelecimentos da cidade são industriais. Comparativamente, se antes podíamos dizer que Jundiaí era uma cidade industrial, hoje parece que essa configuração tem se transformado bastante, principalmente quando verificamos o número de estabelecimentos do setor de serviços e comércio diante do setor industrial de Jundiaí (Tabela 5).

No caso de Várzea Paulista, a densidade urbana da cidade é alta, no entanto a cidade não se destaca em nenhum dos setores, mas é responsável pela oferta de mão de obra para o comércio, o serviço e as indústrias das outras cidades, principalmente Jundiaí e Campo Limpo.

Em Itupeva, identifica-se um eixo de localização de camadas de sociais de renda média alta, através principalmente da expansão de condomínios fechados naquela região, atraídos tanto pela localização entre São Paulo e Campinas, próximos a grandes rodovias, como também pela "qualidade de ambiental" e a presença de microclima próprio da região devido a proximidade à Serra do Japy.

Recentemente foi criado, no sentido de Itupeva, um distrito industrial assim como foi instalado um sistema de gasoduto, atraindo uma vasta gama de indústrias na região, que se localizaram num estratégico entroncamento rodoviário.

Jarinu, apesar de contar com apenas $3,22 \%$ de todos os estabelecimentos do aglomerado, tem $18 \%$ do total dos estabelecimentos da cidade direcionados ao setor agropecuário, assim como tem uma grande área rural $(23 \%)$, se comparada às outras cidades do aglomerado.

Hoje, a maior parte dos deslocamentos diários acontecem em primeiro lugar dentro da própria aglomeração, o que demonstra a forte interação na rede de cidades do AUJ. Em segundo lugar aparecem os deslocamentos diários entre o AUJ para a RMSP, o que reforça a constatação de que a localização do AUJ é muito importante também para o contexto de mobilidade da Macrometrópole Paulista. 


\section{Desafios à mobilidade gerados pelo Aglomerado Urbano de Jundiaí}

A mobilidade urbana no Aglomerado Urbano de Jundiaí estrutura-se basicamente em duas escalas: a cidade e a região, e os fluxos de mobilidade identificam o papel de cada cidade na rede urbana do aglomerado. 0 modo de vida contemporâneo e o dinamismo social conduzem a deslocamentos populacionais, mudanças e redistribuições espaciais, relações e composições entre as cidades, altas densidades e vazios urbanos, a diluição das fronteiras entre as cidades e ao mesmo tempo, o aumento da conexão entre elas.

Uma característica importante das regiões metropolitanas e dos aglomerados urbanos é o movimento de pendularidade intenso nas conexões interurbanas que pode ser notado através da análise do fluxo de transportes coletivos na região, assim como pelo fluxo de veículos de passeio.

A mobilidade é... possibilitada pelas novas tecnologias de comunicação e transporte, permitindo a dissociação residência trabalho, um dos elementos fundamentais da alteração dos padrões de mobilidade diária que ocorreria entre esses dois polos. (Ascher, 1998, apud Marandola, 2006)

O Aglomerado Urbano de Jundiaí é atendido por diversas linhas de transporte coletivo intermunicipal de passageiros com origem e/ou destino internos aos municípios da aglomeração.

Tabela 6 - Transporte coletivo - Número de viagens/dia internas à AUJ

\begin{tabular}{|c|c|c|c|c|c|c|c|c|}
\hline \multirow{2}{*}{$\begin{array}{l}\text { Municípios } \\
\text { de origem }\end{array}$} & \multicolumn{8}{|c|}{ Municípios de destino } \\
\hline & Cabreúva & $\begin{array}{l}\text { Campo } \\
\text { Limpo }\end{array}$ & Itupeva & Jarinu & Jundiaí & Louveira & $\begin{array}{l}\text { Várzea } \\
\text { Paulista }\end{array}$ & Total \\
\hline Cabreúva & 0 & 6 & 0 & 4 & 8 & 0 & 0 & 18 \\
\hline Campo Limpo & 0 & 0 & 0 & 0 & 0 & 0 & 0 & 0 \\
\hline Itupeva & 0 & 0 & 0 & 0 & 0 & 0 & 0 & 0 \\
\hline Jarinu & 0 & 22 & 0 & 0 & 0 & 0 & 0 & 22 \\
\hline Jundiaí & 168 & 283 & 160 & 26 & 0 & 8 & 354 & 999 \\
\hline Louveira & 0 & 0 & 0 & 0 & 0 & 0 & 0 & 0 \\
\hline Várzea Paulista & 0 & 0 & 0 & 0 & 189 & 0 & 0 & 189 \\
\hline Total & 168 & 311 & 160 & 30 & 197 & 8 & 354 & 1.228 \\
\hline
\end{tabular}

Fonte: Emplasa (2007). 
Tabela 7 - Transporte coletivo - Porcentagem de viagens/dia internas na AUJ

\begin{tabular}{l|c|c|c|c|c|c|c|c}
\hline \multirow{2}{*}{$\begin{array}{c}\text { Municípios } \\
\text { de origem }\end{array}$} & Cabreúva & $\begin{array}{c}\text { Campo } \\
\text { Limpo }\end{array}$ & Itupeva & Jarinu & Jundiaí & Louveira & $\begin{array}{c}\text { Várzea } \\
\text { Paulista }\end{array}$ & Total \\
\cline { 2 - 9 } & 0 & 33,3 & & 22,22 & 44,44 & & & 1,466 \\
\hline Cabreúva & 0 & & & & & & & 0 \\
\hline Campo Limpo & 0 & & & & & & & 0 \\
\hline Itupeva & 16,82 & 28,33 & 16,02 & 2,60 & & & & 1,792 \\
\hline Jarinu & & & & & & & & \\
\hline Jundiaí & 13,68 & 25,33 & 13,03 & 2,44 & 16,04 & 0,65 & 28,83 & 1,35 \\
\hline Louveira & & & & & & & 0 \\
\hline Várzea Paulista & & & & & & & & 100 \\
\hline Total & & & & & & & & \\
\hline
\end{tabular}

Fonte: Emplasa (2007).

Pela análise das Tabelas 6 e 7, percebe-se a polarização exercida por Jundiaí na distribuição intrarregional de viagens e passageiros através do transporte coletivo. Aproximadamente $81,35 \%$ dos deslocamentos tem Jundiaí como origem e todos os municípios do aglomerado urbano como destino. Destes $81,35 \%, 35,43 \%$ dirigem-se para Várzea Paulista, 28,32\% para Campo Limpo Paulista, $16,01 \%$ para Itupeva, 16,81\% para Cabreúva e apenas 0,8\% para Louveira. Em síntese, percebe-se, pelos dados, que o município de Jundiaí ocupa a função de centro polarizador da região.
Atualmente, as principais rodovias que ligam as cidades do AUJ têm, em média, um fluxo diário de 60 mil a 80 mil pessoas $^{3}$ em veículos de passeio.

A infraestrutura de rodovias e estradas da região tem sido um dos grandes agentes de desenvolvimento econômico, estimulando o crescimento urbano e a conurbação. Dessa forma, o estudo e a avaliação dos processos geradores da dinâmica socioeconômica são essenciais para se estabelecer as relações de interdependência entre as cidades do aglomerado urbano e também analisar a reestruturação urbana da região. 
Os percursos podem ser vistos como rotas, utilizadas nos deslocamentos das pessoas na cidade, através de espaços livres, que formam trajetórias. Constituem uma linha, no espaço e no tempo, descrita pelo movimento que define a direção de fluxos de circulação cotidianos, podendo indicar vetores de expansão intraurbana. Implicam igualmente num sentido social, relacionado aos deslocamentos e práticas de um dado grupamento humano, em uma direção de crescimento da cidade, englobando questões da cultura, interesses e hábitos típicos dos grupos sociais, em função da localização, renda e modo de transporte urbano. (Silveira et al., 2007)

A partir de Jundiaí é possível perceber vetores de expansão no sentido das metrópoles de São Paulo e Campinas, seguindo os principais eixos rodoviários: pela Rodovia Anhanguera (SP-330), Rodovia Bandeirantes (SP-348) e Rodovia Dom Gabriel Paulino Bueno Couto (SP300), Rodovia Vereador Geraldo Dias (SP-332) e pela Rodovia João Cereser (SP-360).

- pela Rodovia Anhanguera (Cajamar-Jundiaí-Louveira-Vinhedo), as interações urbanas até Campinas são intensas, mas com manchas urbanas fragmentadas, demonstrando uma conurbação funcional (Queiroga e Benfatti, 2007), ou seja, uma intensa relação de dependência econômica e social, através de redes de comunicações sejam físicas ou virtuais, inclusive como o sistema de informações entre as cidades.

- pela Rodovia dos Bandeirantes (São Paulo-Campinas), as interações urbanas até Campinas são menos intensas do que na Rodovia Anhanguera, por se tratar de uma rodovia confinada com poucos acessos ao longo do percurso, embora essa região venha desenvolvendo atividades econômicas atreladas aos parques temáticos e ao turismo de lazer.

- pela Rodovia Dom Gabriel Paulino Bueno Couto (Jundiaí-Itupeva-Cabreúva-Itu), as interações urbanas são mais fortes até Itupeva no sentido de Sorocaba, demonstrando uma conurbação funcional com a implementação do Distrito Industrial, a extensão do gasoduto e a presença de diversos condomínios fechados ao longo da rodovia.

- pela Rodovia Vereador Geraldo Dias (Jundiaí-Louveira-Vinhedo), apresenta-se uma conurbação funcional, no entanto ainda não se verifica uma conurbação espacial, apesar dos fortes indicativos para isso, demonstrando uma tendência de expansão urbana de Jundiaí para o sentido de Campinas.

- pela Rodovia João Cereser (SP-360), articulam-se diretamente as cidades de Jundiaí e Jarinu. Na região de Jundiaí existe um fluxo bastante intenso de circulação de veículos até a Rodovia Engenheiro Constâncio Cintra, que leva a Itatiba, apresentando um fluxo de moderado a intensoaté o acesso a Jarinu, uma cidade com características rurais se comparada as outras cidades do Aglomerado.

A intensidade dos fluxos observados nos eixos viários citados, que absorvem a maioria das trajetórias diárias da população, constitui-se, enquanto aspecto de mobilidade interurbana, num importante indicador da estruturação de vetores de expansão da urbanização não só entre as cidades do próprio aglomerado, mas também entre o AUJ e as Regiões Metropolitanas de Campinas e São Paulo e simultaneamente no ambiente da Macrometrópole Paulista.

Outro indicador significativo da estruturação de um vetor de expansão da urbanização 
no sentido Jundiaí-Itupeva é a constatação de que a evolução da malha urbana de Jundiaí ultrapassou a barreira das rodovias existentes, que se configuravam como tradicionais limites naquela direção. Contribuíram para isso a instalação do Distrito Industrial de Jundiaí e de diversos parques temáticos, localizados às margens da Rodovia Dom Gabriel Paulino Bueno Couto, bem como o Aeroporto de Jundiaí, localizado no vetor sudoeste da cidade. Esses empreendimentos dispersos pelo território consolidaram-se como nós urbanos intrametropolitanos (Queiroga e Benfatti, 2007), apresentando-se como polos geradores potenciais de novas centralidades na escala regional.

Segundo a edição, de 9 de outubro de 2011, do jornal O Estado de S.Paulo, o Aeroporto de Jundiaí tem se destacado como centro da aviação executiva da Macrometrópole Paulista devido ao esgotamento de pistas do Aeroporto de Congonhas e do Campo de Marte. Nos últimos cinco anos, o número de aeronaves e passageiros triplicou, e o jornal destaca como pontos fortes do aeroporto, a questão da localização e do microclima, devido a Serra do Japi, facilitando pousos e decolagens sem o inconveniente da chuva e da neblina.

Hoje, o Aeroporto de Jundiaí faz 78 mil pousos e decolagens de aviação executiva por ano, mais que o dobro de Congonhas (34 mil) e 63\% do movimento total do Campo de Marte.

Essa região geográfica é privilegiada, pois integra uma região densamente povoada, industrializada e com renda per capita expressiva.

Devido aos nós urbanos entre as cidades do Aglomerado, nota-se a fragmentação das manchas urbanas no vetor sudoeste, sentido Itupeva, e no vetor nordeste, sentido Campinas. No sentido Itupeva, é decorrente de processos especulativos e de especulação imobiliária, em que os interesses privados dos empreendedores superam os interesses públicos, como os condomínios fechados, os parques de lazer e o Distrito Industrial de Itupeva. Já no sentido Campinas, essa fragmentação resulta do crescimento de condomínios fechados e da instalação de galpões de logística, situados nas conexões rodoviárias entre os novos tecidos urbanos.

A malha rodoviária e a proximidade de outros meios de transporte facilitam a logística dos produtos e os acessos aos pontos de entretenimento. A conclusão dos rodoaneis de São Paulo e de Campinas (a menos de $50 \mathrm{~km}$ de distância de Itupeva) conectará o município a um grande número de importantes rodovias.

\section{Segregação socioespacial no AUJ}

Essa posição estratégica do AUJ nas conexões intrametropolitanas potencializa a nova unidade regional como localização para moradia, como ponto estratégico para centros logísticos e como local ideal para indústrias de nova geração.

Com a forte infraestrutura rodoviária, facilitando a acessibilidade, a relação espaço-tempo se inverte, e a distância deixa de ser um problema para os deslocamentos diários, intercidades ou intermetrópoles, seja para acesso aos equipamentos de educação, de consumo e serviços, seja para buscar opções de moradia ou trabalho. Dessa forma, a competividade entre as cidades torna-se ainda mais acirrada, agora não só pela população da própria cidade, 
mas pela população de toda a região. Podemos dizer que as cidades deixam de ter suas fronteiras definidas, e o espaço no qual o indivíduo se relaciona também deixa de ser apenas o da própria cidade de residência, ampliando, de forma contemporânea, sua percepção e vivência para a rede de cidades, para o espaço regional.

Segundo Randolph (2010), cada vez mais os processos econômicos ou sociais ultrapas- sam as fronteiras das cidades e provocam al- terações nas relações interurbanas, como a desconcentração de instalações de produção, e interferem na localização dos lugares de trabaIho e das residências da população, ampliando as distâncias, alterando a forma urbana.

Dessa forma, pontos ou sítios tornam-se lugares estratégicos ao permitirem que haja um entrelaçamento e aglomeração de atividades permanentes e estáveis que os tornem centrais (Lefebvre, 1974, p. 331), favorecendo relações interregionais e reestruturando o território.

0 AUJ beneficia-se de sua localização, tornando-se uma plataforma logística, onde tanto produtos como pessoas, tanto bens materiais como bens imateriais (comunicação e informação) se encontram, são recompostos e disseminam-se por toda a região, e isso favore ce uma forte dispersão de assentamentos residenciais, industriais, de serviços e de lazer.

As classes de renda média e renda alta da região têm demonstrado preferência pela região de Itupeva, pois oferece uma malha rodoviária bem estruturada que permite um fácil acesso de veículos de passeio a rede de cidades da Macrometrópole Paulista.

Percebe-se, observando a distribuição geográfica desses dados, o mapa da segregação socioespacial, ou seja, quanto mais próximo de Jundiaí, centro do aglomerado urbano, maior a renda da população.

Jundiaí conta com $59,47 \%$ do PIB do Aglomerado Urbano e, segundo o Índice Paulista de Responsabilidade Social (IRPS), faz parte do grupo de municípios com melhor situação de riqueza e bons indicadores sociais.

Tabela 8 - Índice Paulista de Responsabilidade Social

\begin{tabular}{l|c|c|c|c}
\hline \multirow{2}{*}{ Municípios } & \multicolumn{4}{c}{ IPRS 2008 } \\
\cline { 2 - 5 } & Grupo IPRS & Riqueza municipal & Longevidade & Escolaridade \\
\hline Cabreúva & 2 & 55 & 73 & 65 \\
Campo Limpo Paulista & 2 & 53 & 75 & 65 \\
Itupeva & 2 & 59 & 79 & 66 \\
Jarinu & 3 & 48 & 72 & 68 \\
Jundiaí & 1 & 63 & 76 & 85 \\
Louveira & 2 & 65 & 71 & 51 \\
Várzea Paulista & 2 & 50 & - & - \\
AU Jundiaí & - & - & 73 & 68 \\
Estado de São Paulo & - & 52 & 77 & 50 \\
\hline
\end{tabular}

Fonte: Emplasa (2012). ${ }^{4}$ 
0 Índice de Desenvolvimento Humano o classifica em $1^{\circ}$ lugar dentro do grupo de municípios do aglomerado urbano, na $4^{\mathrm{a}}$ posição entre as cidades paulistas e em $14^{a}$ posição entre as cidades brasileiras.

Segundo o IBGE, o índice de pobreza na cidade de Jundiaí é de $8,78 \%$, um índice bastante baixo diante das outras cidades do aglomerado urbano ou mesmo da cidade de São Paulo e de Campinas.
As cidades que têm o índice mais alto de pobreza na região são Várzea Paulista, com $21,61 \%$, Cabreúva, com $26,73 \%$, e Jarinu, com 27,94\%. Itupeva e Louveira apresentam índices intermediários de pobreza, 18,24\% e 19,54\%, respectivamente. 0 que se pode deduzir da Tabela 9 é que Várzea Paulista, Cabreúva e Jarinu se apresentam como territórios para pessoas de baixa renda e são importantes fornecedores de mão de obra especialmente para Jundiaí.

Tabela 9 - Índice de Desenvolvimento Humano

\begin{tabular}{|c|c|c|c|c|}
\hline \multirow{2}{*}{ Municípios } & \multicolumn{2}{|c|}{ PIB total ${ }^{1}$} & \multirow{2}{*}{$\begin{array}{c}\text { PIB per capita }{ }^{2} \\
\text { (2009 em R\$) }\end{array}$} & \multirow{2}{*}{ IDH 2000} \\
\hline & 2009 em R\$ & $\%$ & & \\
\hline Cabreúva & $1.091 .386 .392,00$ & 3,91 & $25.559,40$ & 0,774 \\
\hline Campo Limpo Paulista & $838.058 .883,00$ & 3,01 & $11.194,57$ & 0,805 \\
\hline Itupeva & $1.736 .231 .142,00$ & 6,23 & $40.892,91$ & 0,789 \\
\hline Jarinu & $399.077 .075,00$ & 1,43 & $17.486,51$ & 0,759 \\
\hline Jundiaí & $16.585 .137 .291,00$ & 59,47 & $47.395,72$ & 0,857 \\
\hline Louveira & $5.815 .328 .590,00$ & 20,85 & $174.891,84$ & 0,800 \\
\hline Várzea Paulista & $1.421 .193 .977,00$ & 5,10 & $13.256,05$ & 0,795 \\
\hline AU Jundiaí & $27.886 .413 .350,00$ & 100,00 & $41.421,58$ & - \\
\hline Estado de São Paulo & $1.084 .353 .489 .626,00$ & - & $26.202,22$ & - \\
\hline
\end{tabular}

(1) (2) - IBGE (2009)

Fonte: Emplasa (2012).

Tabela 10 - Índice de Pobreza por município

\begin{tabular}{c|c}
\hline Municípios & Índice de pobreza em 2010-\% \\
\hline Jundiaí & 8,78 \\
Várzea Paulista & 21,6 \\
Cabreúva & 26,73 \\
Louveira & 17,8 \\
Campo Limpo Paulista & 19,5 \\
Jarinu & 27,94 \\
Itupeva & 18,24 \\
\hline
\end{tabular}

Fonte: IBGE (2012). Disponível em: http://cidades.ibge.gov.br/xtras/home.php 
Essa reconfiguração socioespacial do AUJ é motivada não só pelas relações econômicas, mas também pelas relações sociais, pelo crescimento da segregação socioespacial, pelas estruturas de mobilidades urbanas e pela acessibilidade de locomoção individual e coletiva da população.

As melhorias na infraestrutura, no transporte, nos setores de serviços e comércio, na comunicação urbana têm elevado a taxa de urbanização da rede de cidades, provocando um aumento dos investimentos imobiliários principalmente no município de Jundiaí (ver Gráfico 1). Segundo a Prefeitura Municipal de Jundiaí, o número de imóveis construídos cresceu $38 \%$ do ano de 2000 a 2010.

No entanto, com o crescimento das cidades e da aglomeração urbana, a rede de infraestruturas de rodovias não está sendo capaz de suportar o enorme fluxo de passagens e, causa, consequentemente, congestionamentos nos horários de pico.

A relação entre as cidades do Aglomerado é cada vez mais estreita, uma relação de interdependência, na qual cada uma delas vem assumindo um papel diferenciado como estratégia para se integrar às dinâmicas econômicas e territoriais, onde a soma das cidades não tende ao equilíbrio da região. Assim, a busca de níveis de interação política e de comunicação entre elas, seja através de transportes coletivos, particulares ou pela rede de informática, é cada vez mais essencial a sobrevivência dessas cidades.

Hoje, os entraves à mobilidade urbana nas rodovias entre as cidades do AUJ tornam-se obstáculos às conexões entre a metrópole de São Paulo e de Campinas, e esse problema tende a se agravar, uma vez que o ICGA (Índice de Crescimento Geométrico Anual) da região é o maior da Macrometrópole Paulista.

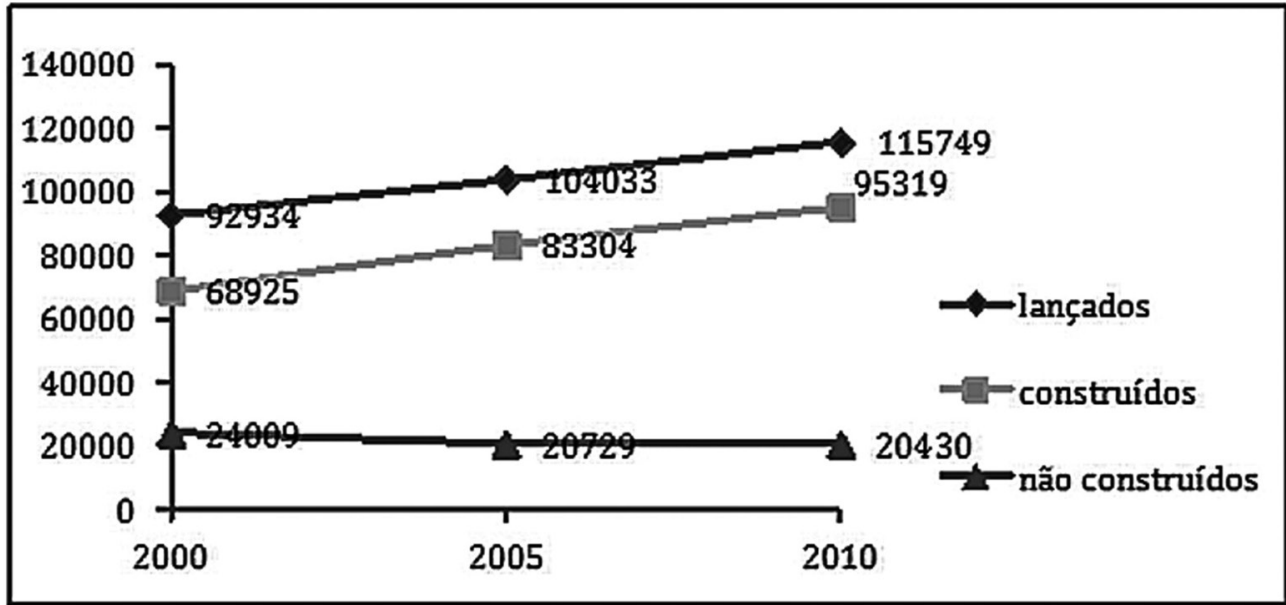


As cidades do Aglomerado Urbano necessitam de planejamento integrado e ação coordenada dos órgãos públicos, para o gerenciamento de problemas comuns, como a questão da mobilidade, segregação social, entre outras desigualdades em nível de saúde, educação e segurança pública. A construção de organismos de gestão regional compartilhada coloca-se como uma questão premente para a obtenção, no contexto descrito por este artigo, de melhorias na qualidade de vida dos habitantes do aglomerado urbano e também da Macrometrópole Paulista, além de aproveitar melhor os recursos públicos, beneficiando o desenvolvimento socioeconômico da região.

A Macrometrópole Paulista é polo de atração de viagens intermunicipais e interestaduais, concentrando fluxos das mais variadas origens e das mais diversas especificidades, simultaneamente fluxos de pessoas e cargas ao longo de suas rodovias, uma vez que nessa região se concentra $50 \%$ do fluxo total de transportes do estado de São Paulo e 93\% de transporte de mercadorias do estado de São Paulo (Asquino, 2010).

Atualmente, o Aglomerado Urbano de Jundiaí caracteriza-se como centro logístico da região, e exatamente nesse ponto nodal, com a grande concentração de transportes de carga, de pessoas, além da presença de mais de 500 empresas ao longo das rodovias, a região encontra-se num momento crítico, pois diariamente apresenta momentos de congestionamentos intensos. Essa situação demonstra a necessidade de um planejamento macrometropolitano na região, pois essa tendência a imobilidade na Macrometrópole tende a aumentar rapidamente. Não podemos apenas correr atrás do problemas já ocorridos, mas além de resolver os existentes e prever eventuais pro blemas futuros.

Cerca de $80 \%$ da carga que circula pela Macrometrópole é considerada carga geral, ou seja, produtos intermediários em suprimento ou escoamento de processos industriais, e produtos para consumo final. Como as instalações de produção e os estabelecimentos de consumo se encontram dispersos por esta região, a logística desta carga torna-se, portanto, de difícil planejamento. (Asquino, 2010)

A capacidade de transformação urbana dessa região é muito grande, provocando realocação de atividades nesse território, atraindo novas atividades ou polos intermetropolitanos que agregam um significativo impacto no sistema viário local. Em virtude da falta de investimentos nos transportes ferroviários, a situação se torna ainda mais agravante nos principais eixos rodoviários.

Nota-se que a manutenção e potencialização do transporte ferroviário, em nível macrometropolitano, torna-se imprescindível, seja no transporte de cargas ou de passageiros. No entanto, no sistema ferroviário atual, existe um conflito de cargas passageiros, pois a constante movimentação de cargas provoca avarias e desgaste nas linhas, impedindo o aumento de velocidade do transporte de passageiros, o que ocasiona muitas paradas ao longo das linhas de trem, comprometendo o aumento da sua velocidade operacional por questão de segurança. Dessa forma, o ideal seria redimensionar o sistema de forma a diferenciar os trens para carga e para passageiros mesmo que na mesma faixa ferroviária, e consequentemente reduzindo o intervalos dos trens da CPTM. 
A melhoria da mobilidade intrametropolitana não deve apenas redimensionar as infraestruturas rodoviárias, mas também expandir os sistemas de transporte sobre trilhos de forma a integrá-los para a solução da mobilidade na atual e futura Macrometrópole Paulista.

\section{Conclusão}

Apesar do AUJ ter a menor área $\left(1.269,99 \mathrm{~km}^{2}\right)$ de todos os aglomerados da Macrometrópole, seu TGCA, de 2000 a 2010, é 1,90 (vide Tabela 2), o maior de toda a região, contrariando a teoria de Christaller de lugares centrais, e justificando a importância do sistema de redes entre cidades.

0 AUJ se beneficia das sinergias dinâmicas entre as metrópoles de Campinas e de São Paulo, responsável por uma posição geográfica chave nas transações inter-regionais (Scott, 1992), articulando ambientes culturalmente diversificados, instituições de ensino importantes, polos de tecnologias de informação e sistemas produtivos importantes para o país, favorecendo uma força de trabalho flexível e criativa, melhorando a acessibilidade para o mundo exterior e numa visão dinâmico do futuro.

Auxiliado por corredores de transporte, como as rodovias e também pela infraestrutura de comunicações, o AUJ vem adquirindo vantagens significativas diante de outros aglomerados na relação tempo e espaço, beneficiando-se pelo transporte de produtos num tempo menor devido a sua localização. Essa rede de cidades possuem uma diversidade de produtos e serviços interessante, seja baseados em conhecimento, como atividades de pesquisa, educação e as artes criativas, seja baseados na produção ou deslocamento logístico.

No entanto, as problemáticas da região teve um crescimento assustador nos últimos anos, tanto com relação a congestionamento como em relação a segregação social. Constatamos rodovias sobrecarregadas tanto pelo transporte de passageiros como pelo escoamento dos produtos desenvolvidos com momentos de imobilidade ao longo do dia. Condomínios fechados competem com as indústrias nessa mesma região intersticial, beneficiando-se da relação espaço-tempo. Além dessa situação, a região, principalmente em direção à Itupeva não está devidamente equipada para receber essa população com grande desnível social. Dessa forma, encontra-se uma região com deficiência na saúde, educação e segurança pública.

Portanto, é nítida a necessidade de planejamento integrado e ação coordenada dos órgãos públicos, para a melhoria na qualidade de vida dos habitantes do Aglomerado Urbano e também da Macrometrópole Paulista, aproveitando melhor os recursos públicos, beneficiando-se do desenvolvimento socioeconômico da região. 


\section{Adriana Fornari Del Monte Fanelli}

Escolas Padre Anchieta e Sociedade Padre Anchieta. Jundiaí/SP, Brasil. amfanelli@uol.com.br

\section{Wilson Ribeiro dos Santos Junior}

Pontifícia Universidade Católica de Campinas. Campinas/SP, Brasil. wilson@puc-campinas.edu.bre wilsonrsj@terra.com.br

\section{Notas}

(1) Nos países desenvolvidos, a intensificação da importância do setor de serviços para empresas ocorre nos anos 1980 e, no final desta década, já se verifica esta tendência em cidades dos países em desenvolvimento que se integram aos mercados mundiais (Davanzo, 2010, p. 90).

(2) Consideram-se arranjos espaciais conjuntos de municípios em continuidade, caracterizados por elevada concentração populacional de renda, taxa de crescimento populacional superior à media dos respectivos estados e significativa mobilidade pendular da população entre municípios. Morfologicamente superam a condição de simples aglomerações por reunirem mais de uma aglomeração e centros urbanos em uma mesma unidade especial, mesmo que descontinuamente (Moura et al. , 2012, p. 52).

(3) Dados fornecidos pela Prefeitura de Jundiaí, 2010.

(4) Grupo IRPS:

- 1) municípios com bons indicadores em riqueza, longevidade e escolaridade;

- 2) municípios bem posicionados na dimensão riqueza, mas com deficiência em pelo menos um dos indicadores sociais;

- 3) municípios com baixos níveis de riqueza, e com bons indicadores de longevidade e escolaridade;

-4) municípios com baixos níveis de riqueza, e com deficiência em um dos indicadores sociais.

\section{Referências}

ANGEL, S.; PARENT, J.; CIVCO, D. L. e BLEI, A. (2012). The Dynamics of Global Urban Expansion. Atlas of Urban Expansion. Lincoln Institute of Land Policy, pp. 1-4.

ASCHER, F. (2001). "Metropolização e transformação dos centros das cidades". In: ALMEIDA, M. A. R. Os centros das metrópoles: reflexos e propostas para a cidade democrática do século XXI. São Paulo, Editora Terceiro Nome/Viva o Centro/Imprensa Oficial do Estado. 
ASQUINO, M. (2010). A importância da Macrometrópole Paulista como escala de planejamento de infraestruturas de circulação e de transporte. Revista Brasileira Estudos Urbanos e Regionais. Rio de Janeiro, v. 12, n. 1, pp. 83-98.

BATTEN, D. (1995). Network Cities: Creative Urban Agglomerations for the 21st Century. Urban Studies, v. 32, n. 2, pp. 313-327.

BOTELHO, A. (2012). Capital volátil, cidade dispersa, espaço segregado: algumas notas sobre a dinâmica do urbano contemporâneo. Cadernos Metrópole. São Paulo, v. 14, n. 28, pp. 297-315.

CUNHA, J. M. P. (2011). Mobilidade espacial da população: desafios tecnológicos e metodológicos para seu estudo. Campinas, Núcleo de Estudos de População/Unicamp.

DAVANZO, A. M. Q.; PIRES, M. C. S.; NEGREIROS, R. e SANTOS, S. M. M. (2010). “Metropolização e rede urbana". In: PEREIRA, R. H. M. e FURTADO, B. A. Dinâmica Urbano Regional: rede urbana e suas interfaces. Brasília, IPEA. Disponível em: http://www.suzanncordeiro.com/wp-content/ uploads/2011/07/Dinâmica+..1.pdf\#page=89. Acesso em: 19 set 2013.

EMPLASA - Empresa Paulista de Planejamento Metropolitano (2011). Rede urbana e regionalização do estado de São Paulo. Disponível em: http://www.emplasa.sp.gov.br/emplasa/ProjetosEstudos/ Relatorios/Livro_miolo\%20em\%20baixa.pdf. Acesso em: 12 abr 2012.

(2012). Disponível em: www.emplasa.sp.gov.br/emplasa/macrometropole/macrometropole. pps. Acesso em: 12 abr 2012 e em 14 abr 2012.

FERRARRI, M. (2011). A metrópole móvel. Pesquisa Fapesp, p. 84. Disponível em: http://revistapesquisa. fapesp.br/wp-content/uploads/2012/04/084-087-184.pdf. Acesso em: 21 set 2013.

IBGE - INSTITUTO BRASILEIRO DE GEOGRAFIA E ESTATÍSTICA (2010). Perfil dos municípios brasileiros 2009 - Pesquisa de Informações Básicas Municipais. Rio de Janeiro, IBGE.

LIMONAD, E. (2011). Urbanização Dispersa mais uma forma de expressão urbana? Revista Formação, v. 1, n. 14, pp. 31-45. Disponível em: www4.fct.unesp.br/pos/geo/revista/artigos/Limonad.pdf . Acesso em: 26 mar 2012.

MARANDOLA, E. (2006). Mobilidade e vulnerabilidade nos espaços de vida de Campinas. In: XV ENCONTRO NACIONAL DE ESTUDOS POPULACIONAIS. Anais. Caxambu/MG.

MONTE-MÓR, R. L. (1994). "Urbanização extensiva e lógicas de povoamento: um olhar ambiental”. In: SANTOS, M. et al. (org.). Território, globalização e fragmentação. São Paulo, Hucitec/Anpur.

MOURA, R. (2004). Morfologias de concentração no Brasil: o que se configura além da metropolização no Brasil? Revista Paranaense de Desenvolvimento. Curitiba, n. 107, pp. 77-92.

MOURA, R.; LIRA, S. A. e CINTRA, A. P. U. (2012). Arranjos espaciais: concentração e mobilidade que redesenham as aglomerações e centros. Caderno IPARDES. Curitiba, v. 2, pp. 51-67.

QUEIROGA, E. F. e BENFATTI, D. M. (2007). Entre o nó e a rede, dialéticas espaciais contemporâneas: o caso da metrópole de Campinas diante da megalópole do Sudeste do Brasil. Revista Brasileira de Estudos Urbanos e Regionais, v. 9, n. 1.

QUEIROGA, E. F.; SANTOS JR., W. R. e MERLIN, J. R. (2009). Sistemas de espaços livres e metrópole contemporânea: reflexos a partir do caso da região metropolitana de Campinas. Paisagem Ambiente: ensaios. São Paulo, n. 26, pp. 211-223. 
RANDOLPH, R. (2011). A questão da fronteira das metrópoles e a reorganização regional em seu entorno: reflexões a respeito de mudanças do paradigma da urbanização. In: XIV ENCONTRO NACIONAL DA ANPUR. Anais. Rio de Janeiro. Disponível em: http://www.anpur.org.br/site/ anais/ena14/ARQUIVOS/GT9-556-531-20110106090645.pdf. Acesso em: 18 out 2012.

SASSEN, S. (1998). As cidades na economia mundial. São Paulo, Studio Nobel.

(2008). The specialised diferences of global cities. Arquitextos. Disponível em: www.vitruvius. com.br/revistas/read/arquitextos/09.103/87. Acesso em: 5 jun 2012.

SCOTT, A. J.; AGNEW, J.; SOJA, E. W. e STORPER, M. (2001). Cidades-regiões globais. Espaço e Debate. São Paulo, n. 41, pp. 41-25.

SEADE - Fundação Sistema Estadual de Análise de Dados (2012). Informações dos municípios paulistas: Jundiaí, Louveira, Itupeva, Jarinu, Cabreúva, Várzea paulista e Campo Limpo. População. Taxa de urbanização. Disponível em: http://www.seade.gov.br/produtos/imp/index. php?page=consulta\&action=var_list \&tabs=1\&aba=tabela3\&redir=\&busca=Popula\%E7\%E3o. Acesso em: 14 abr 2012.

(2012). Informações dos Municípios paulistas: Jundiaí, Louveira, Itupeva, Jarinu, Cabreúva, Várzea Paulista e Campo Limpo. População. TGCA. Densidade Demográfica e Área. Disponível em: http://www.seade.gov.br/produtos/imp/index.php?page=consulta\&action=var_list\&tabs= 1\&aba=tabela3\&redir=\&busca=Popula\%E7\%E3o. Acesso em: 14 abr 2012.

SILVEIRA, J. A.; LAPA, T. A. e RIBEIRO, E. L. (2007). Percursos e processo de evolução urbana: uma análise dos deslocamentos e da segregação na cidade. Arquitextos 090.04. Disponível em: http:// www.vitruvius.com.br/revistas/read/arquitextos/08.090/191. Acesso em: 5 jun 2012.

VILLAÇA, F. (2001). Espaço intraurbano no Brasil. São Paulo, Studio Nobel/Fapesp/Lincoln Institute. (2012). Reflexões sobre as cidades brasileiras. São Paulo, Studio Nobel.

\section{Sites consultados}

- Empresa Paulista de Planejamento metropolitano. Emplasa (em linha). Disponível em: http://www. emplasa.sp.gov.br. Acesso em: 12 abr 2012 e em 14 abr 2012.

- Instituto Brasileiro de Geografia e Estatísticas. IBGE. Disponível em: http://www.ibge.gov.br. Acesso em: 12 abr 2012 e em 14 abr 2012.

-Prefeitura Municipal de Jundiaí. Disponível em: http://www.jundiaí.sp.gov.br. Acesso em: 14 abr 2012.

- Fundação Sistema Estadual de Análise de Dados-Seade - 2012. Disponível em: www.seade.gov.br. Acesso em: 14 abr 2012.

-Secretaria deDesenvolvimentoMetropolitano. Disponível em:http://www.sdmetropolitano.sp.gov.br/ portalsdm/faces/pages_index?_afrWindowld=bo8bmzbzh_1\&_afrLoop=863285833853464\&_ afrWindowMode=0\&_adf.ctrl-state=bo8bmzbzh_4. Acesso: em 18 set 2013.

Texto recebido em 10/mar/2013

Texto aprovado em 22/ago/2013 
